\title{
Democracia digital: uma análise sobre recursos e aceitação
}

\section{Alternative Title: Digital democracy: an analysis of resources and acceptance}

\author{
Bárbara P. Caetano ${ }^{12}$, Guilherme W. de Oliveira1 ${ }^{1}$ Melise M. V. de Paula1', Jano M. de Souza ${ }^{2}$ \\ UUniversidade Federal de Itajubá \\ Av. BPS, 1303, Pinheirinho, Itajubá, \\ MG, Brasil \\ ${ }^{2}$ COPPE - Universidade Federal do Rio de Janeiro \\ CP: 68511 - 21941-972, Rio de Janeiro, RJ, Brasil \\ \{bpimentacaetano, jano\}@cos.ufr..br
}

\{werneck.guilherme, melisepaula\}@unifei.edu.br

\begin{abstract}
RESUMO
O avanço tecnológico tem influenciado a relação entre o governo e o cidadão. Nesse cenário, surge o tema Democracia Digital que estimula o Estado na adoção de estratégias que viabilizem a atuação do cidadão não como cliente das informações disponibilizadas, mas como agente catalisador da democracia. Paralelo a esta vertente, observa-se as mudanças no que diz respeito ao entendimento do exercício da cidadania. Contudo, a democracia digital é um fenômeno que necessita de elucidação tanto em relação aos diversos recursos disponibilizados quanto à aceitação dessas novas possibilidades de participação social. Neste artigo, será descrita uma pesquisa exploratória que procurou compreender este fenômeno. $\mathrm{O}$ estudo foi realizado a partir de três linhas de ação: revisão bibliográfica, análise de recursos disponíveis e pesquisa de opinião. Nesta última, foram entrevistadas 220 pessoas através de um questionário online. A investigação mostrou que há diferentes iniciativas que convergem para graus de democracia digital semelhantes. Além disso, a pesquisa de opinião indicou um nível consistente de aceitação da utilização da tecnologia neste contexto.
\end{abstract}

\section{Palavras-Chave}

Democracia Digital, Governo Eletrônico

\begin{abstract}
Technological advances have influenced the relationship between government and citizen. In this scenario, the Digital Democracy theme that encourages the state to adopt strategies that enable the performance of the citizen not as a client of the information provided, but as a catalyst for democracy, arises. Parallel to this, changes can be observed with regard to the understanding of citizenship. However, digital democracy is a phenomenon that requires clarification both in relation to the various resources available as in the acceptance of these new possibilities for social participation. In this article, an exploratory study that sought to understand this phenomenon will be described. The study was conducted from three lines of action: literature review, analysis of resources available and survey research. In the survey, 220 people were interviewed via an online questionnaire. Research shows that there are different initiatives converge to similar degrees of
\end{abstract}

Permission to make digital or hard copies of all or part of this work for personal or classroom use is granted without fee provided that copies are not made or distributed for profit or commercial advantage and that copies bear this notice and the full citation on the first page. To copy otherwise, or republish, to post on servers or to redistribute to lists, requires prior specific permission and/or a fee.

SBSI 2016, May 17-20, 2016, Florianópolis, Santa Catarina, Brazil. Copyright SBC 2016 digital democracy. Moreover, the survey showed a consistent level of acceptance of the use of technology in this context.

\section{Categories and Subject Descriptors \\ H.4.0 [Information System Applications]: General}

\section{General Terms}

Management, Human Factors.

\section{Keywords}

Digital Democracy, e-Government

\section{INTRODUÇÃO}

Atualmente, a capacidade de participação política da sociedade tem sido modificada pelos diversos avanços tecnológicos. As novas movimentações sociais associadas às novas possibilidades de comunicação e mobilização exigem um novo arranjo na relação entre a esfera política e civil.

Neste cenário, a democracia vem sendo analisada sob a perspectiva da mediação da tecnologia. Em Trechsel et al. [23], os autores definem o termo e-Democracia ou Democracia Eletrônica que consiste em todos os recursos que permitam o envolvimento efetivo dos cidadãos na decisão, ação e julgamento das ações dos governantes.

Para Penteado, Araújo e Santos [16], a democracia digital não significa uma nova forma de democracia e sim o uso da Web para sua consolidação. As novas possibilidades tecnológicas podem ser consideradas catalisadoras de um novo cenário político no qual o espaço de participação da sociedade nas decisões políticas necessita ser rediscutido e ampliado.

Um exemplo desta nova modalidade de organização e ação da sociedade são as novas estratégias de mobilização. Em Araújo, Penteado e Santos [2], os autores afirmam que o ativismo da sociedade ganhou novas formas e discutem o webativismo (ciberativismo) como sendo um conjunto de práticas realizadas em rede com objetivo de ampliar a colaboração da sociedade na defesa de causas específicas. Segundo os autores, o webativismo amplia as possibilidades da sociedade pressionar o Estado a modificar as decisões e implementar políticas públicas que atendam às necessidades e demandas destes grupos sociais.

É possível notar uma movimentação dos cidadãos neste sentido. O trabalho realizado por Maia [15] mostrou uma grande movimentação da população no Twitter quando o prefeito de São Paulo anunciou o aumento do IPTU em 2013. Além da mobilização, a participação da esfera civil nos processos de decisões políticas pode ser definida em diferentes graus. Para Gomes[9], a visão de que os meios e agentes de comunicação de 
massa funcionam somente como cães de guarda do Estado é extenuada, embora seja parcialmente verdadeira. De acordo com o autor, a democracia digital deve assegurar a intervenção do público nos processos de decisão política podendo até mesmo, em um maior grau de participação da sociedade, permitir que a decisão política seja do cidadão que passa agir como um produtor de decisão. A convergência entre os sistemas de informação de governo, a democracia digital e a computação para multidão pode auxiliar o crescimento da participação dos cidadão na gestão pública. Para Magdaleno [14], identificar os requisitos e desenhar arquiteturas flexíveis que tragam um nível de engajamento e participação esperado, são alguns dos desafios encontrados no momento de projetar ferramentas que suportam a interação nos sistemas de informação de governos abertos e colaborativos.

A proposta deste artigo é descrever um estudo realizado com objetivo de estimular a compreensão e familiarização com o tema democracia digital. Para isto, foi executada uma pesquisa exploratória definida a partir de três linhas de ação: levantamento bibliográfico, análise de um conjunto de recursos tecnológicos associados ao tema e um levantamento estatístico que permitiu identificar a opinião pública de uma amostra sobre alguns aspectos relacionados à democracia digital. Vale destacar que não fez parte do escopo deste problema confirmar ou refutar hipóteses. O objetivo foi obter uma visão geral e atual sobre a democracia digital, os recursos disponíveis e a aceitação sob a ótica de um grupo de cidadãos.

\section{REVISÃO BIBLIOGRAFICA}

A visão da Internet como local público virtual atribui ao cidadão o direito de se comunicar mais livremente sendo fonte e receptor de informações ao mesmo tempo. Este cenário impulsiona novos tipos de relação uma vez que amplia as possibilidades de comunicação e socialização. Os atos políticos podem ser considerados um exemplo de relações influenciadas por este cenário e a democracia digital faz parte deste ambiente.

A democracia digital pode ser definida como uma forma de se praticar governo eletrônico, na qual a população pode interagir de forma direta com a administração pública, exercendo seus direitos políticos [7]. Para Landim [12], o conceito de democracia digital está diretamente ligado ao uso de dispositivos, como computadores, celulares, aplicativos e ferramentas, que alimentam discussões sobre práticas políticas e sociais da própria nação.

Como qualquer outra forma de política, a democracia digital também tem seus limites. Sampaio [20] e Lüchmann [13], afirmam que, antes de qualquer coisa, é preciso ter vontade política e que o Estado deve considerar os recursos tecnológicos como elementos fundamentais em sua gestão política e desenvolvimento urbano. Além disso, deve haver interesse da população para que as tecnologias sejam ferramentas benéficas para a gestão. Segundo Landim [12], os debates políticos realizados através de redes sociais, como o facebook, só se sustentam a partir do momento em que há uma alta adesão e legitimidade. Ao contrário disso, os debates não representam nenhum tipo de participação.

Na literatura, é possível identificar uma diversidade de trabalhos relacionados ao tema que vão desde a análise da democracia digital a partir de iniciativas específicas como, por exemplo, Hayashi, Rothberg e Hayashi [10], Curran e Singh [4], Gillespie [8], redes sociais como Landim [12] e Rothberg [18] até reflexões sobre o fenômeno e suas implicações como Lüchmann [13], Rover [19] e Sampaio [20].
Gomes [9] descreveu cinco graus de participação popular proporcionados pela Internet que o autor denominou graus de democracia digital.

O primeiro grau é basicamente descrito como a prestação de serviços do Estado para o cidadão. Ou seja, o Estado disponibiliza informações básicas e serviços relacionados à saúde, segurança, transportes, arrecadação de impostos e outros recursos que promovem ou tentam promover a desburocratização. Silva [21] descreve o fluxo de interação deste grau como uma via de mão única, o objetivo principal é a tornar a prestação de serviços do governo mais eficiente, através do uso de tecnologias de comunicação. No primeiro grau, duas funções são observadas na relação política entre o Estado e o cidadão. $\mathrm{Na}$ primeira, o governo procura suprir a necessidade da informação básica, serviços e bens públicos. Já na segunda, o cidadão recebe, sem transtornos e de forma rápida, os serviços públicos oferecidos, fazendo com que assuma o papel de consumidor. Neste grau, a produtividade e o funcionamento saudável da máquina estatal são características almejadas [21].

O segundo grau é caracterizado pela participação do cidadão através de consultas realizadas pelo governo a respeito de temas da agenda pública. Gomes [7] diz que nesse grau de democracia, há uma sondagem da opinião pública obtida através do contato direto com a esfera civil. Isso mostra que o Estado possui certo nível de porosidade com a população. Com isso, a sensibilidade à opinião pública depende da vontade deliberacionista do Estado, característica que pode ser alcançada com o uso das ferramentas tecnológicas. Segundo Silva [21], nesse grau de democracia existe algo próximo a um canal de comunicação, mas a emissão ainda continua sendo de mão única. Além disso, o autor também afirma que nem todas as informações recolhidas da população serão utilizadas para a tomada de decisão política, ou seja, não existe um diálogo efetivo entre a esfera civil e o governo que emita sinais de receber algum tipo de retorno.

Nos dois primeiros graus de democracia, o fluxo da comunicação parte da esfera política em direção à esfera civil, obtendo feedback e retornando as informações para os agentes públicos. Essa forma de comunicação é mais conhecida como G2C (government to citizen), algo que tem sido muito utilizado nos dias atuais. Por outro lado, em graus mais elevados de democracia digital o fluxo de comunicação se inicia na esfera civil [9].

Para Gomes [7], no terceiro grau, o Estado busca um alto nível de transparência para o cidadão, característica que não é observada no grau anterior. Para atingir esse objetivo, a esfera política gera um intenso volume de contas e informações a prestar, ou seja, o Estado se orienta por um princípio de publicidade política esclarecida. Entretanto, o Estado ainda não conta com a população para a produção da decisão política. Como a transparência é um ponto forte nesse grau, o Estado se esforça para eliminar a política do segredo, buscando eliminar barreiras que impeçam a população de obter o conhecimento da gestão pública.

O quarto grau se baseia nos conceitos da democracia deliberativa. Assim, processos e mecanismos de discussão são criados para se produzir, de comum acordo com a população, decisões políticas. Silva [21] ressalta que nesse grau a esfera política ainda se mantém como agente essencial para a tomada de decisão. Entretanto, se torna mais poroso à participação popular intervindo deliberativamente nas decisões políticas [9].

Já no quinto grau de democracia digital, a esfera política não existiria mais, pois o próprio público controlaria a decisão política no interior do Estado. Sua implantação causaria uma mudança 
drástica no modelo democrático. Silva [21] afirma que "numa democracia digital de quinto grau, prevalece a ideia de que, com as possibilidades interativas em massa das novas tecnologias da comunicação, a decisão deveria estar assim transferida diretamente para a esfera civil". Nesse grau o ideal da democracia direta seria buscado através das TIC, fazendo a esfera política tomar apenas um papel representativo. Para Allan [1], a democracia, assim como outras esferas, está sofrendo uma grande influência da Internet. Com isso, a tecnologia tem o poder de desconstruir a democracia representativa em que vivemos, tornando os cidadãos mais influentes na gestão pública. $\mathrm{O}$ autor ainda afirma que a tecnologia tem mudado muito o cenário político, alterando, até mesmo, as campanhas políticas. Atualmente, as campanhas digitais têm sido consideradas efetivas e essenciais para qualquer campanha política de sucesso.

\section{INICIATIVAS E RECURSOS}

O objetivo desta seção foi descrever, em linhas gerais, alguns dos recursos e iniciativas identificados que estão de alguma maneira associados ao processo de democracia digital. Além disso, para que fosse possível relacionar de modo mais claro estes recursos com o tema democracia digital, os mesmos foram classificados de acordo com os graus de participação da esfera civil nos processos de decisões políticas definidos por Gomes [9].

No primeiro grau, há várias iniciativas em disponibilizar informações e serviços online aos cidadãos. Um exemplo de iniciativa é a organização internacional Digital Democracy, que tem como missão capacitar comunidades marginalizadas a utilizar tecnologias para defender seus direitos. Outro exemplo de iniciativa internacional é o Instituto de Tecnologia e Sociedade do Rio, uma associação civil sem fins lucrativos. No Brasil, a disponibilização de dados é um compromisso firmado pelo governo brasileiro no Open Government Partnership. Além disso, a Lei de Acesso a informação [11] torna obrigatória a disponibilização de informações básicas à população, o que força a criação de diferentes recursos que convergem para o primeiro grau de democracia. Na literatura, é possível encontrar diferentes trabalhos nos quais os autores avaliam o efeito desta lei no processo democrático. Em Bernardes, Santos e Rover [3], por exemplo, os autores fizeram uma análise de como a lei está sendo implementada pelas prefeituras da região Sul tendo em vista o cumprimento das disposições nela estabelecidas. São diversos os serviços disponibilizados sejam na esfera federal, estadual ou municipal. No Portal da Polícia Federal, por exemplo, para realizar o pedido do passaporte, é possível preencher o requerimento, verificar a documentação necessária, agendar atendimento, emitir a GRU entre outros. O Sistema de Seleção Unificada (Sisu) também é outro exemplo de processo fortemente apoiado pela tecnologia. Outros exemplos de iniciativas no Brasil podem ser encontrados no Portal Brasil, no Portal de Serviços do Governo Federal e no site do Ministério do Trabalho e Emprego. $\mathrm{Na}$ esfera estadual, um exemplo seria o site do Governo de Minas Gerais. Exemplos na esfera municipal podem ser os sites da Prefeitura do Rio de Janeiro e da Prefeitura de Salvador.

Muitos recursos podem ser classificados no segundo grau. O governo federal, por exemplo, disponibiliza a plataforma Participa.br e o Programa e-Cidadania. O participa.br é um ambiente virtual de participação social com o objetivo de promover a interação entre administração pública e sociedade civil, divulgação de conteúdo, fóruns de debate, salas de bate papo, entre outras funcionalidades. O Programa e-Cidadania oferece ferramentas para a interação no processo de fiscalização, no processo legislativo, e para interação direta com Senadores.
Desta forma, é possível expressar opinião sobre temas de interesse da sociedade, acompanhar o orçamento brasileiro e as ações administrativas do Senado, além da possibilidade de propor novas leis e alteração da legislação vigente. Ainda no segundo grau, há iniciativas que não estão vinculadas a um governo específico. A Rede Nossas Cidades, por exemplo, é uma rede de ativismo e mobilização que reúne mais de 250 mil pessoas em diferentes cidades. No site são disponibilizadas ferramentas desenvolvidas pela rede. Entre elas a ferramenta Panela de Pressão, que permite contato direto com governantes, gestores públicos, parlamentares, concessionárias de serviços públicos, políticos em geral e outros tomadores de decisão das cidades. Outra possibilidade é a ferramenta Legislando, que permite que os cidadãos participem ativamente do processo de criação de leis em suas cidades. Por fim, a rede disponibiliza a ferramenta Imagine que proporciona um ambiente em que é possível conhecer os problemas e imaginar ideias para solucioná-los.

Outro exemplo é o Konsento, uma organização não governamental que promove a democracia digital direta e o consenso progressivo. A meta da organização é a construção de um software, de código aberto, em que qualquer cidadão poderá se cadastrar, propor e participar de discussões. Além disso, a organização se propõe a pressionar os políticos para que analisem as ideias caso haja consenso entre os cidadãos. A plataforma CitiesFor.life é mais um exemplo de recurso classificado no segundo grau. Utilizando um ambiente muito parecido com uma rede social, permite que o usuário insira sugestões para melhorias nas cidades e dê opinião em outras sugestões. A pretensão é que seja utilizada por usuários de todo o mundo, mas inicialmente possui apenas usuários e discussões da cidade de Medellin na Colômbia.

No terceiro grau, se enquadram todas as iniciativas do Estado em promover a transparência de maneira que, tendo mais acesso a informação, a sociedade tenha mais poder de influenciar a esfera política. No Brasil é possível encontrar algumas iniciativas do Governo Federal que convergem para este grau. O Portal Brasileiro de Dados Abertos, por exemplo, funciona como um catálogo de dados publicados pelos órgãos do governo. Outro exemplo de recurso é o Portal VisPublica, que utiliza técnicas de visualização de informação para apresentar, com maior transparência, dados públicos. Uma alternativa para disponibilização desses dados é através de interfaces de programação de aplicações (API) de dados. No Brasil, um exemplo é a API de Compras do Governo Federal.

No quarto grau de participação, embora a esfera política continue a existir, a decisão é da sociedade. No cenário atual, ainda são poucas as iniciativas que promovem este tipo de relação entre Estado e sociedade. Contudo, para efeito desta análise, é possível considerar os plebiscitos, referendos e iniciativas populares como iniciativas do quarto grau. Estes recursos foram instituídos como instrumentos de democracia na Constituição de 1988 [26]. Em 2011, por exemplo, foi realizado no Brasil um plebiscito em que os cidadãos do Estado do Pará foram consultados, através de votação, sobre a divisão do Estado e a criação do Estado do Carajás e do Estado do Tapajós [17]. Quanto ao quinto grau, considerando a drástica mudança que causaria no modelo democrático vigente, não foram encontradas iniciativas que atendessem fielmente este ponto. Contudo, foram identificados movimentos que defendem esta perspectiva. O DemoEx - Partido da Democracia Experimental Brasileiro (PDEB), por exemplo, é um projeto de partido político que tem como proposta implementar processos, regras e mecanismos de capacitação para fortalecer a democracia participativa e mobilizar a sociedade. 


\section{OPINIÃO PÚBLICA E A DEMOCRACIA DIGITAL}

Na terceira linha de ação, o objetivo foi investigar a opinião pública de uma amostra em relação à viabilidade de participação da população no processo democrático e à aceitação de uso da tecnologia como catalisadoras deste processo.

O método utilizado foi uma pesquisa quantitativa cuja coleta dos dados foi realizada através de um questionário. O propósito foi exploratório sendo que a unidade de análise considerada foi um grupo da sociedade que tivesse acesso a algum tipo de ferramenta tecnológica como, por exemplo, computador ou celular. $\mathrm{O}$ questionário foi divulgado via correio eletrônico e redes sociais. As perguntas elaboradas podem ser classificadas em dois grupos:

G1: as perguntas deste grupo foram apresentadas com o objetivo de investigar a opinião dos participantes em relação à viabilidade de participação da população no processo democrático. Basicamente, o questionamento que tentou ser elucidado foi: A sociedade pode contribuir com a gestão pública para a tomada de decisão? Para isto, foram elaboradas as seguintes perguntas: P1(Você gostaria de participar do governo dando sua opinião em decisões tomadas pelos gestores?), P2(Você acredita que atualmente discussões e debates entre diversos cidadãos sobre assuntos públicos pode auxiliar e colaborar com a resolução de questões que envolvam a sociedade?) e P3(Você acredita que seria possível o poder público utilizar opiniões de cidadãos na tomada de decisão do governo?).

G2: para as perguntas deste grupo, o objetivo foi analisar a aceitação de uso da tecnologia como catalisadoras do processo democrático. $\mathrm{O}$ ponto de questionamento foi verificar se, na opinião dos participantes, uma ferramenta computacional pode auxiliar a sociedade permitindo que os cidadãos contribuam com a gestão pública diminuindo as possíveis dificuldades em discutir assuntos públicos com uma grande quantidade de cidadãos de uma forma rápida. Além disso, outra questão elucidada foi a disposição das pessoas em colaborar.

$\mathrm{Na}$ literatura, é possível encontrar diferentes abordagens para análise de aceitação e uso da tecnologia da informação. Em VENKATESH et al. [25], os autores apresentam uma síntese de oito modelos/teorias de aceitação do uso de tecnologia que resultaram na Teoria Unificada da Aceitação e Uso da Tecnologia (UTAUT) que pode ser considerada uma tentativa de combinar a dispersa literatura sobre o assunto e desenvolver uma única teoria capaz de elucidar vários aspectos à respeito da aceitação da tecnologia para usuários finais [22]. Em 2012, VENKATESH et al. [24] apresentaram uma evolução da UTAUT, a UTAUT2 que é definida a partir de 9 categorias cognitivas conceituais, denominadas constructos: expectativa de performance (grau no qual o uso de uma tecnologia pode prover benefícios na execução de determinadas tarefas), expectativa de esforço (grau de facilidade associado ao uso da tecnologia), influência social (grau no qual os outros percebem a importância do uso da tecnologia), facilitadores (percepção em relação à disponibilidade de recursos que facilitam o uso da tecnologia), motivação hedônica (refere-se à motivação ou satisfação provocados pelo uso da tecnologia), preço (valor relativo entre o benefício proporcionado e o custo do uso da tecnologia) e o hábito (grau de automaticidade do uso da tecnologia após seu aprendizado) [6].

De acordo com a UTAUT2, a expectativa de performance e de esforço, a influência social, as condições facilitadoras, a motivação hedônica, o preço e o hábito estão relacionados com a intenção de usar um determinado recurso tecnológico (comportamento de intenção de uso). Já a própria intenção de uso, as condições facilitadoras e o hábito influenciam o comportamento de uso que reflete a maneira como a tecnologia é usada [6, 24]. Além disso, os autores afirmam que a idade, o sexo e a experiência exercem alguma influência nestes constructos. De acordo com Faria et al. [5], após sua publicação, o modelo tornouse fundamento para estudos que se utilizavam da totalidade ou de parte de seus constructos a fim de analisar a aceitação e o uso de tecnologia em diversos contextos.

Neste trabalho, o UTAUT 2 foi usado parcialmente. É importante deixar claro que no estudo que está sendo apresentado, a análise não se refere a uma tecnologia específica. Desta forma, os constructos foram considerados somente como diretriz para a elaboração do questionário no sentindo de apontar elementos que poderiam contribuir na investigação. Como o objetivo do grupo G2 é analisar a intenção de uso, foram considerados os seguintes constructos: eficiência de performance, influência social e a motivação hedônica. As perguntas do grupo G2 associadas ao constructo correspondente são: P4 - Você acha interessante um sistema online em que qualquer cidadão pudesse opinar sobre assuntos públicos? (Motivação hedônica); P5 - Você acredita no funcionamento deste tipo de ferramenta como um instrumento de aproximação da sociedade com a gestão pública? (Eficiência de performance); P6 - Você acredita que em longo prazo este tipo de ferramenta seria uma alternativa para ajudar na mobilização da sociedade que se apresenta, muitas vezes, desorganizada? (Eficiência de performance); P7 - Você costuma se interessar por assuntos da gestão pública? (Motivação hedônica); P8 - Você costuma analisar informações sobre a gestão pública? (Motivação hedônica); P9 - Se existisse um sistema online em que fosse possível discutir e debater sobre assuntos públicos você utilizaria? (Motivação hedônica); P10 - Se você tivesse informação à respeito de uma questão em discussão em uma ferramenta, você estaria disposto à compartilhar esta informação com outros cidadãos? (Motivação hedônica, influência social); P11 - Se você soubesse a solução para um problema em discussão em uma ferramenta, você estaria disposto a propor esta solução? (Motivação hedônica, influência social); P12 - Você estaria disposto a opinar sobre as soluções propostas por outros cidadãos? (Motivação hedônica, influência social).

A estratégia usada para coletar as informações foi apresentar uma escala de Likert de 5 pontos de forma que o usuário pudesse indicar seu nível de concordância. É importante deixar claro que as respostas propostas originalmente na escala (discordo fortemente e concordo fortemente) foram adaptadas de maneira que se adequassem ao questionário. Duas possíveis métricas que podem ser derivadas dos resultados é a soma da quantidade de respostas com maiores graus de concordância (concordo e concordo fortemente), para indicar o grau de aceitação, e a soma da quantidade de respostas discordo e discordo fortemente, para indicar o grau de rejeição. As perguntas com suas respectivas respostas estão descritas nas Figuras 1 a 12 da seção 4.1 nas quais são apresentados os resultados.

\subsection{Análise dos Resultados}

Foram respondidos 220 questionários, sendo $62,3 \%$ do sexo masculino e $37,7 \%$ do sexo feminino. Além das perguntas já descritas, foram solicitadas algumas informações de forma a definir o perfil da amostra. A faixa etária foi distribuída em dois grupos: menos de 26 anos (36,9\%), mais de 26 anos $(63,1 \%)$. Foi questionado se o participante ocupava algum papel no governo (Possui algum papel no governo?) e se participava de alguma 
organização não governamental associada às questões da gestão pública (Participa de alguma associação ou organização não governamental associada às questões da gestão pública?). Estas informações foram coletadas, pois estes vínculos podem influenciar na percepção do participante em relação à aceitação da democracia digital. Somente $22,7 \%$ dos participantes exercem algum papel no governo.

Além disso, 91,4\% não participam de ONG relacionadas à gestão pública. Desta forma, os resultados demonstram que a amostra considerada é formada basicamente por pessoas sem uma associação direta com o funcionalismo público e sem uma inserção direta em questões de governo. Ainda em relação ao perfil, 98,6\% dos participantes afirmaram usar a internet com frequência. Este resultado permite concluir que a amostra considerada é compatível com a unidade de análise definida.

Quanto ao primeiro ponto de investigação (Grupo G1), os resultados obtidos com as perguntas $\mathrm{P} 1, \mathrm{P} 2$, e P3 (representados nas Figuras 1, 2 e 3, respectivamente) indicam que a maioria dos participantes acredita na viabilidade da sociedade participar de forma mais ativa do processo democrático. Especificamente, na $\mathrm{P} 1$, os entrevistados demonstraram ter interesse em participar, somente $15,5 \%$ se declararam indiferentes e apenas $11,4 \%$ (soma dos valores 1 e 2 da escala) mostraram uma tendência forte de não gostar desta participação.

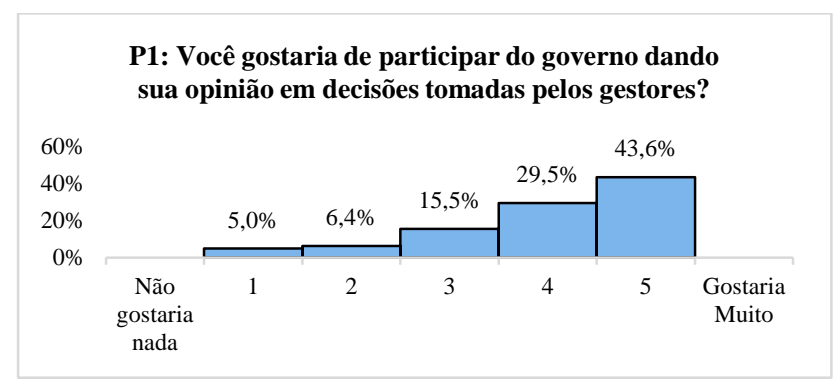

Figura 1. Resultados da P1

\begin{tabular}{|c|c|c|}
\hline \multicolumn{3}{|c|}{ 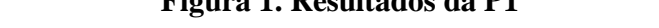 } \\
\hline \multicolumn{3}{|c|}{$\begin{array}{l}\text { P2: Você acredita que discussões e debates entre } \\
\text { diversos cidadãos sobre assuntos públicos pode } \\
\text { auxiliar e colaborar com a resolução de questões que } \\
\text { envolvam a sociedade? }\end{array}$} \\
\hline $\begin{array}{l}\text { Acredito que discussões e debates } \\
\text { possam colaborar com a resolução de } \\
\text { questões públicas. }\end{array}$ & & $39,50 \%$ \\
\hline $\begin{array}{c}\text { Acredito que discussões ... com } \\
\text { algumas restrições. }\end{array}$ & & $49,1 \%$ \\
\hline Indiferente. & $2,70 \%$ & \\
\hline $\begin{array}{l}\text { Não acredito que discussões e debates } \\
\text { possam colaborar com a resolução de } \\
\text { questões públicas no contexto atual. }\end{array}$ & $3,60 \%$ & \\
\hline $\begin{array}{l}\text { Não acredito que discussões e debates } \\
\ldots \text { independente do contexto. }\end{array}$ & $3,20 \%$ & \\
\hline
\end{tabular}

\section{Figura 2. Resultados da P2}

Além do interesse, os resultados da P2 (Figura 2) e P3 (Figura 3) mostram que a maioria dos participantes tende a dar credibilidade a esta participação. Na P2, foi analisada a credibilidade em relação à eficiência desta participação, ou seja, o quão útil seria esta relação. Menos de $10 \%$ se declararam indiferentes ou desacreditados em algum grau.
Na P3, foi analisada a percepção dos participantes quanto à possibilidade do Estado usar efetivamente a sociedade no processo decisório, $74,5 \%$ dos participantes acreditam nesta sinergia em algum grau, mesmo que $27,7 \%$ deste subtotal não tenham concordado fortemente com a resposta correspondente ao maior grau de aceitação.

P3: Você acredita que seria possível o poder público utilizar opiniões de cidadãos na tomada de decisão do governo?

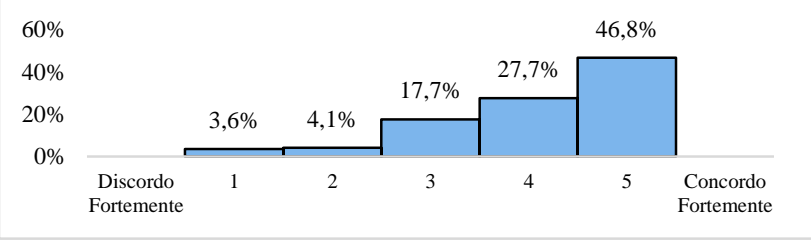

Figura 3. Resultados da P3

Para o grupo G2, a análise foi realizada considerando os constructos definidos na UTAUT2 [24]. Quanto à eficiência de performance, a maioria dos participantes demonstram uma percepção positiva em relação à efetividade do uso de uma ferramenta como um facilitador da aproximação entre poder público e sociedade. Na P5 (Figura 4), 88,2\% dos entrevistados afirmaram acreditar no funcionamento deste tipo de ferramenta, embora 47,7\% tenham afirmado acreditar com alguma restrição. Já na P6 (Figura 5), o aspecto analisado foi a possibilidade de uma ferramenta apoiar a mobilização da sociedade que é extremamente importante para qualquer processo democrático. Considerando as respostas relacionadas à não aceitação, somente $3,1 \%$ afirmaram não aceitar, em algum grau, a utilidade de uma ferramenta neste contexto.

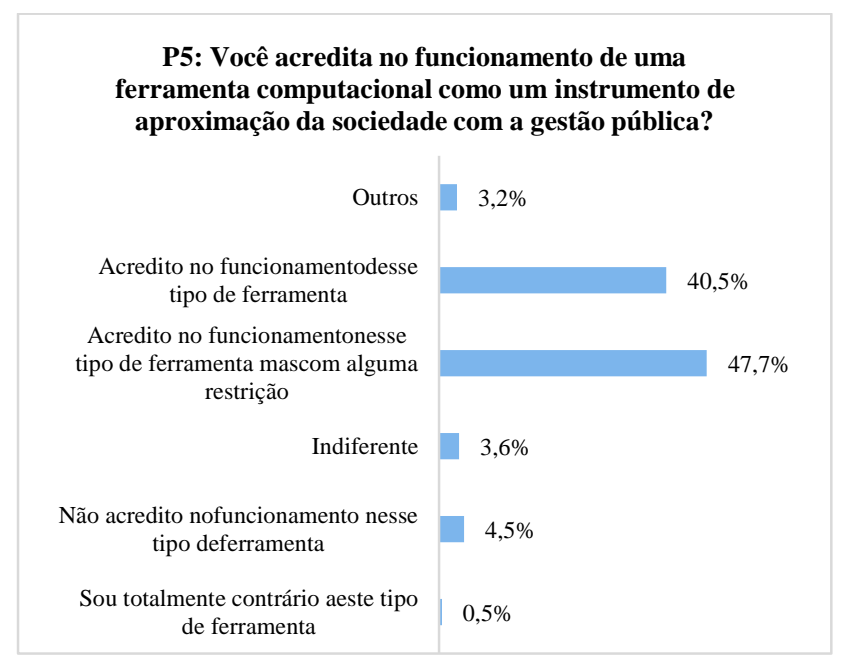

Figura 4. Resultados da P5

Nas duas questões relacionadas à eficiência de performance, o participante poderia optar por não selecionar uma resposta específica e incluir um comentário. Na P5 (Figura 4), 3,2\% dos entrevistados fizeram algum tipo de comentário, já na P6 (Figura 5 ), foram $0,9 \%$. Dentre eles, alguns foram somente repetições das respostas apresentadas. Contudo analisando os demais, é possível fazer algumas considerações: o anonimato foi definido como sendo importante; o desinteresse da sociedade foi considerado um problema; deve existir uma preocupação com a acessibilidade. 
P6: Você acredita que em longo prazo este tipo de ferramenta pode ajudar na mobilização da sociedade que se apresenta, muitas vezes, desorganizada?

\begin{tabular}{|c|c|c|}
\hline Outro & $0,9 \%$ & \\
\hline $\begin{array}{l}\text { Acredito que este tipo de ferramenta } \\
\text { pode proporcionar alguma organização } \\
\text { e mobilização da sociedade }\end{array}$ & & $51,8 \%$ \\
\hline $\begin{array}{l}\text { Acredito que este tipo de ferramenta } \\
\text { pode ... mas com alguma restrição }\end{array}$ & & $41,4 \%$ \\
\hline Indiferente & $2,7 \%$ & \\
\hline
\end{tabular}

Não acredito que este tipo de

ferramenta pode proporcionar alguma $\quad 2,3 \%$

organização e mobilização da.

Sou totalmente contrário a esta ideia

de que este tipo de ferramenta pode | $0,9 \%$ proporcionar ..

\section{Figura 5. Resultados da P6}

Quanto à motivação hedônica, como o fenômeno estudado é a democracia digital, a motivação para o uso da tecnologia tem uma relação direta com o interesse das pessoas pelo assunto gestão pública. Nas perguntas P7 (Figura 6) e P8 (Figura 7), este aspecto foi analisado. A quantidade de pessoas que afirmaram ser indiferentes é relevante. Considerando a soma dos dois maiores índices da escala de Likert (4 e 5), o menor valor obtido foi nas perguntas $\mathrm{P} 7$ e P8, o mesmo acontece se considerar somente o maior índice (5). Embora não faça parte do escopo deste trabalho analisar detalhadamente este aspecto, é importante constatar que embora a aceitação da tecnologia esteja apresentando uma tendência positiva, o interesse da sociedade em participar ativamente da política pode ser um fator limitante.

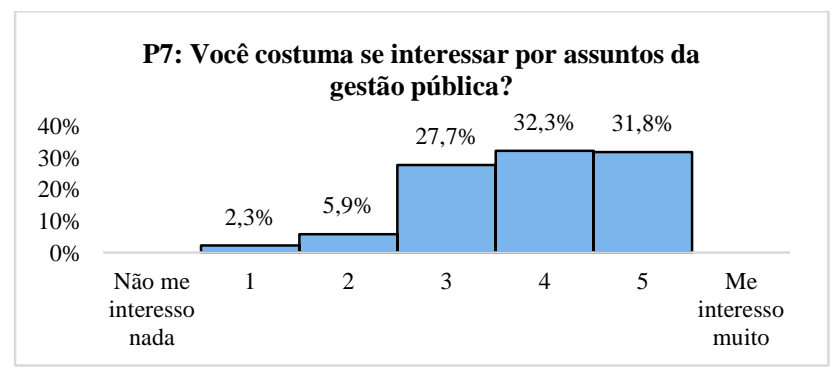

Figura 6. Resultados da P7

P8: Você costuma analisar informações sobre a gestão pública?

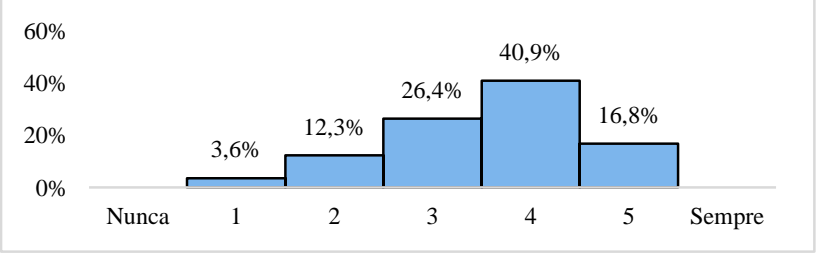

Figura 7. Resultados da P8

As perguntas P4 (Figura 8) e P9 (Figura 9) se relacionam ainda com o constructo motivação hedônica, mas investigam o uso específico da ferramenta e não o processo subjacente. Os resultados indicam uma quantidade expressiva de participantes que estariam motivados a usar este tipo de tecnologia, pois $90,4 \%$ afirmaram achar, em algum grau, este tipo de sistema interessante

(Figura 8). Além disso, 91,4\% demonstraram uma predisposição a usar e indicar este tipo de sistema (Figura 9).

\section{P4: Você acha interessante um sistema online em que qualquer cidadão pudesse opinar sobre assuntos públicos?}

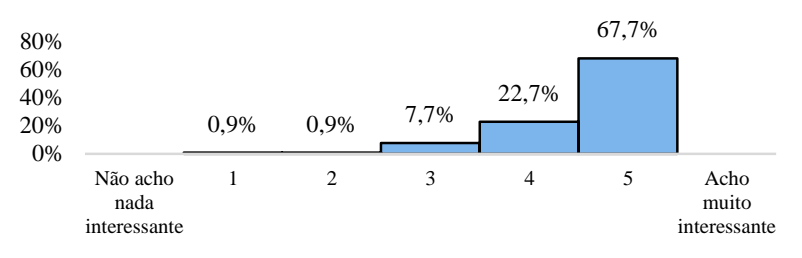

Figura 8. Resultados da P4

As perguntas P10 (Figura 10), P11(Figura 11) e P12 (Figura 12) foram associadas à motivação hedônica e influência social. A possibilidade de compartilhar informações/opiniões sobre problemas/assuntos da gestão pública, subjetivamente, pode demonstrar alguma preocupação com o reflexo da sua participação naquele grupo e algum contentamento que advêm não somente da utilização da ferramenta, mas também da possibilidade de participar de uma discussão.

Os resultados com a P11 (Figura 11) demonstram que os respondentes apresentam alguma inclinação para participar da solução de problemas através do uso da ferramenta, somando os maiores índices da escala, $87,8 \%$ dos entrevistados afirmam que gostariam de propor uma solução em algum grau.

A predisposição em colaborar seja fornecendo novas informações ou opinando sobre outras soluções também fica evidente com os resultados da P11 (Figura 11) e P12(Figura 12).

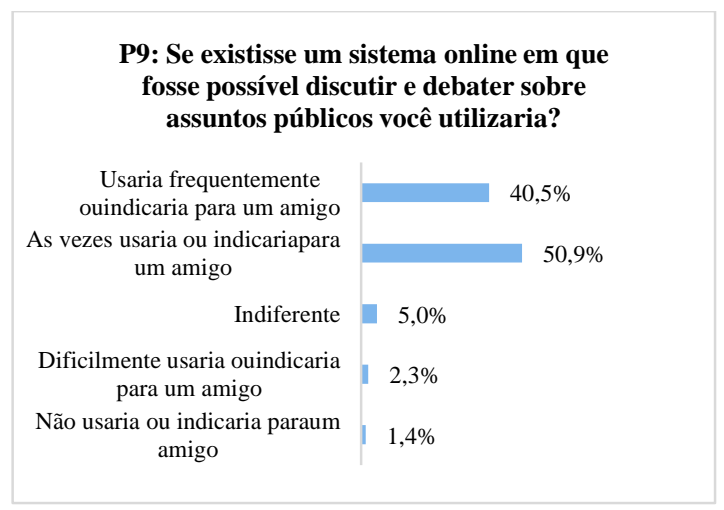

Figura 9. Resultados da P9

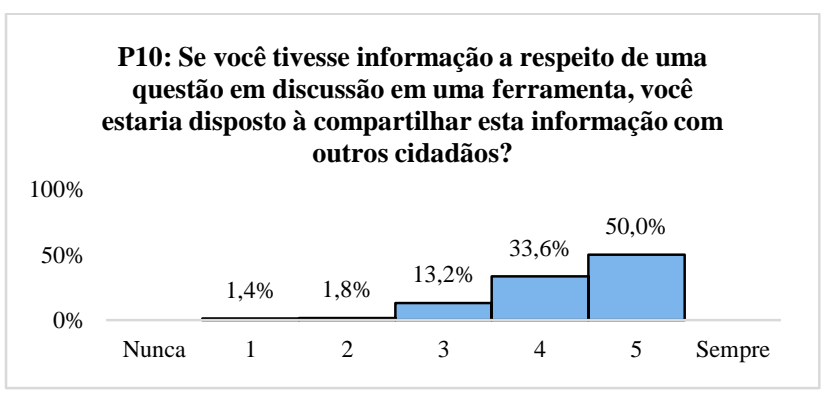

Figura 10. Resultados da P10

Além dos dados já apresentados, foram definidos seis novos grupos de dados considerando o sexo, idade e a relação com governo. O objetivo desta nova análise foi verificar se estas variáveis iriam exercer alguma influência nos resultados obtidos. 
Os novos grupos definidos foram: grupos por sexo (feminino e masculino), grupos por faixa etária (menores ou igual a 25 anos e maiores que 25 anos) e grupos por relação com governo (grupos de pessoas que possuem alguma relação profissional com governo e grupos de pessoas sem vínculo com o governo).

Os resultados obtidos nesta análise não apresentaram diferenças significativas entre os grupos. Considerando a limitação de espaço, apenas algumas representações gráficas elaboradas serão apresentadas.

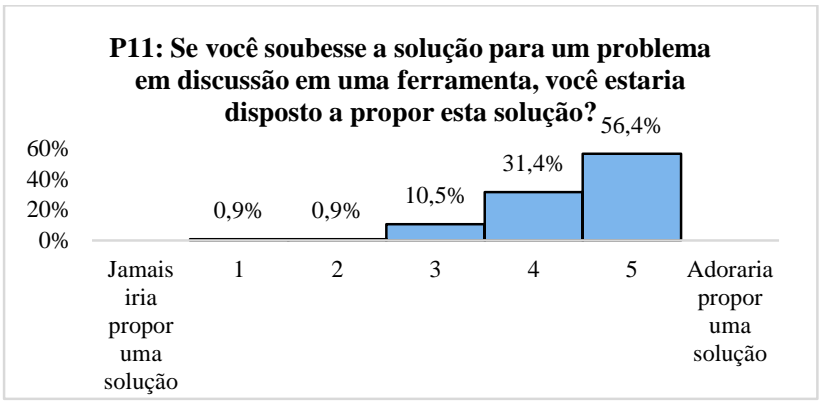

Figura 11. Resultados da P11

P12: Você estaria disposto a opinar sobre as soluções propostas por outros cidadãos?

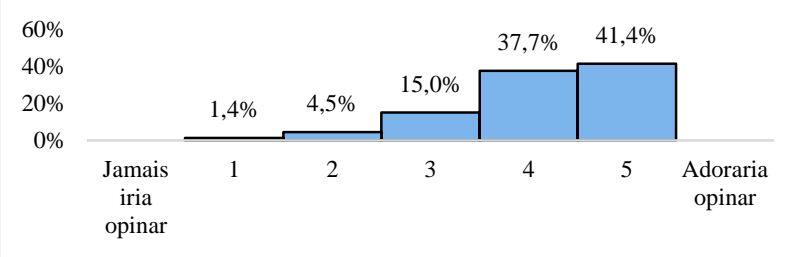

Figura 12. Resultados da P12

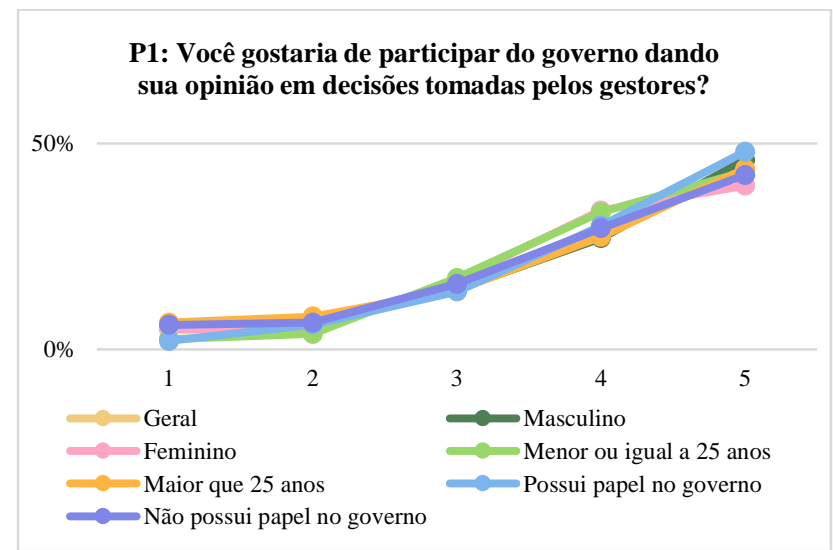

Figura 13. Pergunta P1 para os 6 grupos analisados

A Figura 13 ilustra os resultados obtidos com a pergunta P1, os números no eixo horizontal do gráfico correspondem às respostas. As curvas definidas pelos grupos seguem a mesma tendência. Este comportamento se repete para as demais perguntas.

Embora em alguns casos, seja esperada alguma diferença relacionada ao sexo, no caso deste trabalho, a amostra se mostra relativamente homogênea quanto a este elemento. Este comportamento pode ser justificado pelo perfil da amostra que foi composta basicamente por pessoas com acesso ao computador e alguma experiência na utilização da Internet. A mesma justificativa pode ser aplicada ao aspecto idade.
Contudo, foi possível constatar que para as perguntas P7 e P8, houve uma diferença relevante em relação à faixa etária. No gráfico da Figura 14 (Pergunta P7), os participantes com menos de 25 anos são os que mais afirmaram ser indiferentes aos assuntos da gestão pública. Além disso, a curva que representa este grupo cai a partir do valor 3 sendo que a tendência das demais é de alta. No gráfico da Figura 15 (Pergunta P8), embora todas as curvas tenham caído a partir do valor 4 (eixo horizontal), a curva correspondente ao grupo com menos de 25 anos novamente reflete um maior número de indiferentes e uma tendência de queda a partir do valor 3

\section{P7: Você costuma se interessar por assuntos da gestão pública?}

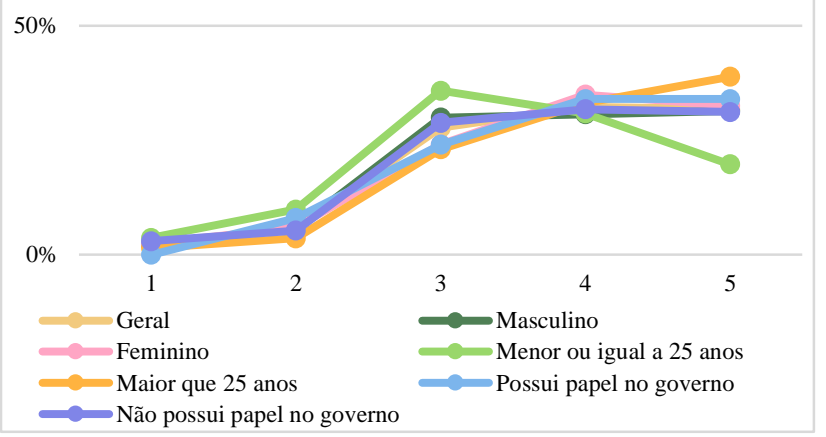

Figura 14. Pergunta P7 para os 6 grupos analisados

P8: Você costuma analisar informações sobre a gestão pública?

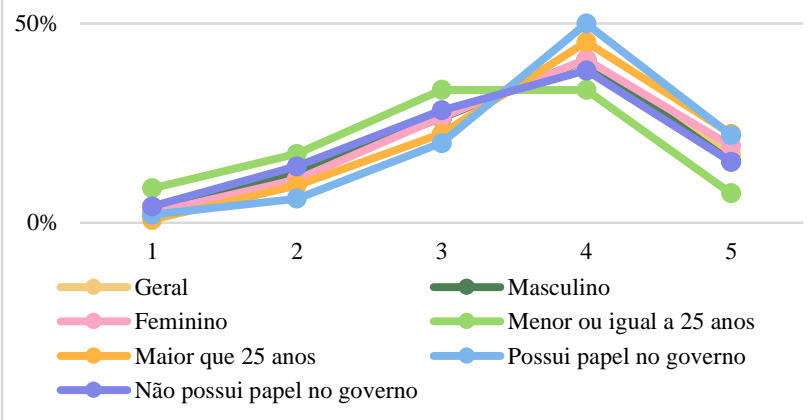

Figura 15. Pergunta P8 para os 6 grupos analisados

\section{CONCLUSÃO}

Este trabalho está inserido no contexto de uma pesquisa cujo objetivo é propor soluções efetivas para participação igualitária dos cidadãos no processo de gestão pública através da convergência entre duas áreas: Democracia Digital e Computação para Multidão. Para isto, o ponto inicial foi investigar o fenômeno democracia digital e alguns aspectos que estão sujeitos a esta análise. $\mathrm{O}$ estudo apresentado possui natureza exploratória seguindo duas vertentes: a análise de recursos já disponíveis e a investigação da aceitação do uso deste tipo de tecnologia.

A análise dos recursos permitiu concluir que já existem algumas práticas e iniciativas relacionadas à ampliação do ato de governar. Considerando os diversos graus de democracia digital descritos, algumas iniciativas apresentam desdobramentos ou aplicações importantes em tecnologias e ambientes digitais.

Outra constatação é que a maioria destes recursos não leva a uma extensão da democracia e sim a alguma estratégia de correção dos problemas encontrados neste processo. Mesmo sendo possível 
constatar um aumento de poder da população através da liberdade de expressão e acesso a informação, as barreiras políticas, econômicas e culturais ainda não evidentes.

Embora não seja pretensão discutir amplamente estes aspectos, pode-se colocar alguns apontamentos. A barreira política reflete a necessidade de constituir um modelo de transição do modo de governar, partindo do representativo para o participativo. A barreira econômica se estende em várias vertentes que vão desde a dificuldade de acesso aos recursos tecnológicos, que ainda é uma realidade, até os requisitos necessários para a elaboração de soluções tecnológicas que permitam explorar de maneira eficiente a sabedoria humana. É neste último aspecto que se encaixa a associação deste estudo com a Computação para Multidão.

Por fim, em relação às barreiras sociais, uma reflexão importante é o interesse do cidadão em questões políticas. Considerando a pesquisa de opinião realizada, a amostra analisada indicou uma aceitação consistente desta população na utilização de tecnologias relacionadas ao exercício da democracia. Contudo, foi possível constatar também que, embora significativo, o interesse por questões políticas isoladas se apresenta um pouco menor.

Pode ser apontado como limitação deste trabalho o fato de não ter sido utilizado um método sistemático para revisão da literatura e seleção dos recursos utilizados. Além disso, o tamanho da amostra pode ser considerado limitado para o levantamento realizado.

Desta forma, conclui-se que a agenda de pesquisa nessa área é ainda extensa e se ramifica em vários temas. Ainda que parte destes temas extrapole o aspecto tecnológico, há uma necessidade clara de convergir esforço no sentido de buscar soluções que ultrapassem o caráter corretivo do processo.

\section{REFERENCIAS BIBLIOGRÁFICAS}

[1] Allan, R. 2009. New technologies, same old politics. Nature. 458, 7237 (2009), 409-410.

[2] Araújo, R. de P.A. et al. 2015. Democracia digital e experiências de e-participação: webativismo e políticas públicas. Hist. ciênc. saúde-Manguinhos. 22, supl (2015), 1597-1619.

[3] Bernardes, M.B. et al. 2015. Ranking das prefeituras da região Sul do Brasil: uma avaliação a partir de critérios estabelecidos na Lei de Acesso à Informação. Revista de Administração Pública. 49, 3 (2015), 761-792.

[4] Curran, T. and Singh, R. 2011. E-democracy as the future face of democracy: a case study of the 2011 Irish elections. European View. 10, 1 (2011), 25-31.

[5] Faria, L.H.L. et al. 2014. Applicability of Unified Theory of Acceptance and Use of Technology Extended to the Consumer Use Context (UTAUT2) in Brazil: An Evaluation of the Model Using a Sample of Internet Users on Smartphones. Revista de Administração da UFSM. 7, 2 (2014).

[6] Farias, J.S. et al. 2015. A Propensão De Usuários À Adoção De Tecnologias: Um Estudo Com Usuários E Não Usuários Do Programa "Nota Legal" No Distrito Federal. (2015).

[7] Farias, V.V.M. 2013. As Possibilidades da Democracia Digital no Brasil. Mídias e direitos da sociedade em rede (2013), 495-509.

[8] Gillespie, M. 2013. BBC Arabic, social media and citizen production: An experiment in digital democracy before the Arab Spring. Theory, Culture \& Society. 30, 4 (2013), 92130 .
[9] Gomes, W. 2005. A democracia digital e o problema da participação civil na decisão política. Fronteiras-estudos midiáticos. 7, 3 (2005), 214-222.

[10] Hayashi, M.C.P.I. et al. 2010. Scientific knowledge and digital democracy in Brazil: how to assess public health policy debate with applied Scientometrics. Scientometrics. 83, 3 (2010), 825-833.

[11] LAI: A Lei de Acesso à Informação: http://www.acessoainformacao.gov.br/assuntos/conhecaseu-direito/a-lei-de-acesso-a-informacao/a-lei-de-acessoa-informacao. Accessed: 2016-02-28.

[12] Landim, I.C. 2013. Um estudo sobre a relação entre a Democracia Digital e a Participação Política a partir do debate sobre o Programa Mais Médicos no Facebook. Revista Mídia e Cotidiano. 3, 3 (2013), 538-561.

[13] Luchmann, L.H.H. 2002. Possibilidades e limites da democracia deliberativa: a experiência do Orçamento Participativo de Porto Alegre. (2002).

[14] Magdaleno, A.M. and ARAUJO, R. 2015. Ecossistemas Digitais para o Apoio a Sistemas de Governo Abertos e Colaborativos. Simpósio Brasileiro de Sistemas de Informação. 1, (2015).

[15] Maia, G.M. et al. Democracia Eletrônica e Mineração de Texto no Twitter.

[16] Penteado, C.L. et al. Internet, Políticas Públicas e Participação Política Online: avaliação de experiências de eParticipação. Encontro Internacional Participação, Democracia e Políticas Públicas: aproximando agendas e agentes.

[17] Plebiscitos no Estado do Pará: http://www.tse.jus.br/eleicoes/plebiscitos-ereferendos/plebiscitos-no-estado-do-para. Accessed: 201602-25.

[18] Rothberg, D. 2014. Democracia digital e redes sociais: Twitter como filtro de informação política. (2014).

[19] Rover, A.J. 2006. A democracia digital possível. Seqüência; Estudos Jurídicos e Políticos. 27, 52 (2006), 85.

[20] Sampaio, R.C. 2009. Governança eletrônica no Brasil: limites e possibilidades introduzidos pelo Orçamento Participativo na Internet. Planejamento e Políticas Públicas. (2009), 123-144.

[21] Silva, S.P. da 2005. Graus de participação democrática no uso da Internet pelos governos das capitais brasileiras. Opinião Pública. 11, (2005), 450-468.

[22] Slade, E.L. et al. 2013. An extension of the UTAUT 2 in a healthcare context. Proceeding of the UK Academy for Information Systems. (2013).

[23] Trechsel, A.H. et al. 2003. Evaluation of the use of new technologies in order to facilitate democracy in Europe. C2D-Research and Documentation Centre on Direct Democracy.

[24] Venkatesh, V. et al. 2012. Consumer acceptance and use of information technology: extending the unified theory of acceptance and use of technology. MIS quarterly. 36, 1 (2012), 157-178.

[25] Venkatesh, V. et al. 2003. User acceptance of information technology: Toward a unified view. MIS quarterly. (2003), 425-478.

[26] 1988. Constituição da República Federativa do Brasil de 1988. 